\title{
INTO DARKNESS
}

At the edge of science.

\section{BY ANIKE KIRSTEN}

iya peered over her shoulder at the micro black hole that floated ready to swallow her. Its void cut a circle in the cerulean Zimbabwe sky. She gripped the rope in her hands and adjusted the harness fastened to the bridge. Leaves rustled as a gust of wind surged from below. Her blue radiation suit fluttered. The hole's secrets would be revealed, one way or another.

For the most part, it shouldn't exist within the laws of physics, yet here it hovered in front of Victoria Falls. Her and Busi's creation, and their greatest achievement after years of research. According to the calculations, the gravitation was too weak to bend space-time enough to cause any physical damage. Busi assured her it was safe. Her maths had better be correct.

"Ready?" Busi leant on the railing beside her.

Siya nodded. "Now or never." Her heart pounded against her chest and she could feel the pulse in her neck. She turned to face the black hole and, with a deep breath, let go.

Busi stayed behind to record the measurements. They needed the data to figure out what exactly was inside a black hole. Or near enough of one. The knowledge no one else had. It was either her or Busi who had to go in. Much too risky to bring anyone else into the loop.

Siya had drawn the short straw.

She scanned the void enveloping her. There seemed no end to the black. Siya's gloved fingers stretched and warped. The rope from the harness drifted above, like gravity didn't exist. Was she still falling, or floating?

The watch Busi had given her for Christmas vibrated. Forty-five minutes remaining before her oxygen depleted.

She stared at the small screen on the watch that warped with her wrist like a Dalí painting. Radiation levels were non-existent. Was that possible? She stretched out a waving arm and an invisible surface blocked her from feeling farther. She slid her gloved hand across it - smooth and domed.

The watch vibrated again. Thirty minutes left.

Curling her legs to her chest, Siya pressed her feet against the surface then stood upright. The small amount of light that

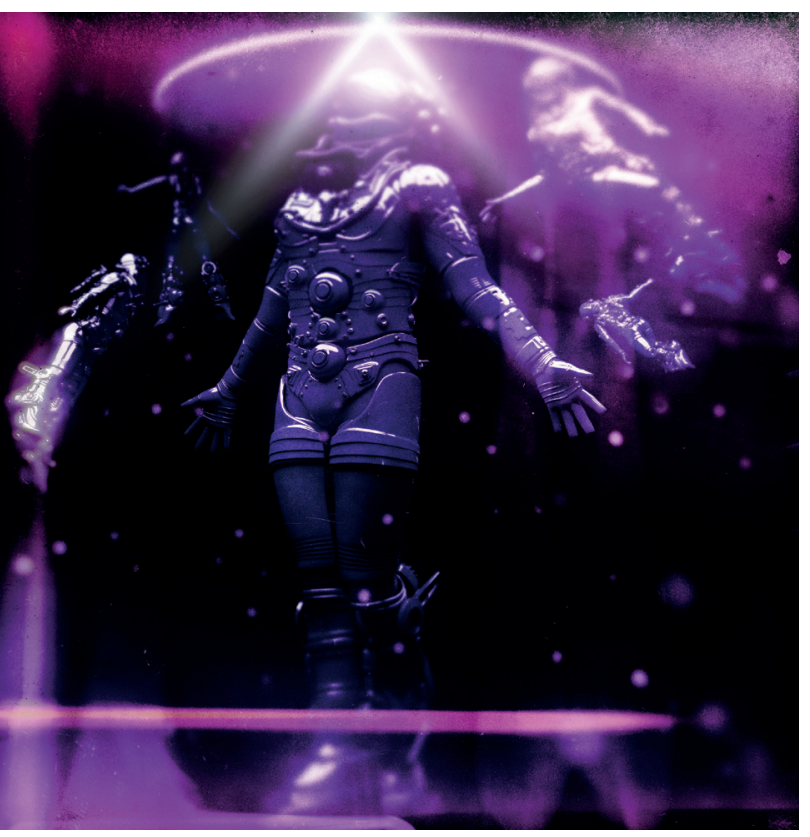

with her. Bugger the risks. But why had Busi done this? She couldn't have held a grudge all this time. Siya getting into university first wasn't in anyone's control.

They had made a pact always to be together, graduate together and make discoveries. But Busi wasn't accepted for another two years after. This wasn't like her at all. Had she never forgiven her? The black hole wasn't the only danger.

The watch vibrated again. Five minutes. Time was up.

Above, another figure suspended in the black hole's event horizon, descending into darkness. Their blue suit seemingly frozen. The lifeline from their harness drifted - cut. Siya looked at the rope in her hand. Déjà vu.

Her watch vibrated once more. Forty-five minutes.

This couldn't be. Unless their cal-

survived the weak gravitation illuminated a figure below. Siya bent down and found a gap in the invisible surface. She slipped through it. A cut rope floated around the figure ahead as they drifted, motionless, their arm stretched out as though reaching for her.

Her watch vibrated. Twenty minutes. Still no radiation.

"Hello?" Keeping close to the invisible barrier, Siya manoeuvred towards the person. How did anyone get in here? Was this a hallucination? "I'm coming, just hang on." With a kick, she pushed off the smooth surface and floated down. The distance between them seemed to grow.

"Take my hand." No reaction. No movement. "Can't you hear me?" Of course they couldn't. Still, it felt wrong not to call out.

The air in her suit grew stuffy and she struggled to breathe.

Siya grabbed their rope and pulled the person closer. They still didn't move. A fog hid their face inside the helmet of the blue suit. She shook their shoulders. No response. Siya felt in the dark for another surface. Nothing. She tugged the rope attached to her harness - no resistance - and looked back.

Cut. How had Siya not realized it before? The pieces fell together like rain in a pothole, collecting to become whole. Busi.
ONATURE.COM Follow Futures:

\section{y @NatureFutures}

$f$ go.nature.com/mtoodm
They should have brought in someone else to throw in here, not her. Someone who didn't have a history culations were wrong. Could space-time have bent enough in here to affect light like this? Siya checked her oxygen level. Almost depleted. She looked at the person beside her, still unresponsive. Faint light reflected off a watch on their wrist. The same as the one Siya had. On it, the timer stalled at 30 minutes and 33 seconds.

Her breaths laboured as she tried to get closer to the new figure, still falling, floating. "Turn back before you're too deep inside. You won't get out - I won't get out." She stretched a hand above her head then, using the person's body to kick against, launched forward. Anything to stop her past-self. Her future-self?

The heat of her breath settled on the screen of her helmet, forming a fog that blurred her vision. There was no way out. Even if she could escape the black hole, what was the point? Busi was still out there, and she had probably planned for anything.

But Siya had to try. She had to warn herself. Get out!

With one more deep breath, she reached out as the figure ahead stood upright on an invisible surface.

Her watch vibrated -30 minutes and 33 seconds.

Anike Kirsten is a South African writer of science fiction and sometimes other genres. Her work has been published or is forthcoming in 600 Second Saga and Illumen. 